\title{
"Como abelhas polinizando flores": gerência e racionalização do trabalho no complexo coureiro-calçadista de Franca, SP, no século $X^{1}{ }^{1}$
}

\author{
"As bees pollinating flowers": labor management \\ and rationalization in the leather and shoe \\ complex (Franca, SP, Twentieth Century)
}

Vinícius de Rezende*

\section{Resumo}

A partir da segunda metade do século XX, a cidade de Franca (SP) tornou-se o principal centro produtor de calçados masculinos de couro do Brasil. O artigo demonstra que esse processo inseriu-se nas transformações mais amplas do capitalismo industrial no período. Para tanto, analisa-se a mecanização e a racionalização da produção de couros, calçados e seus artefatos, conferindo especial atenção à importação de profissionais, de técnicas de gestão e tecnologias por parte das maiores indústrias locais. Dessa maneira, objetiva-se compreender como a interação entre os industriais nacionais e os de países tecnologicamente mais avançados, aliada à atuação de tecnólogos estrangeiros, possibilitou a difusão de princípios gerenciais e organizacionais formulados em indústrias de ponta de países como os Estados Unidos da América e a Tchecoslováquia.

Palavras-chave: industrialização; racionalização; gerência.

\section{Abstract}

The city of Franca (SP) was the major centre of production of male leather shoes in Brazil in the second half of the twentieth century. In this paper I explore how it was largely connected to the great transformations of industrial capitalism. In doing so, I analyse the mechanization and rationalization of the production of leather, footwear and its components, looking especially to the process of acquisition of managers, management techniques and technologies by the major local industries. More specifically my goal is to understand how the relationship between national industrialists and industrialists from countries technologically advanced, such as the agency of foreign managers, enabled to diffusion of managerial and organisation rules achieved at advanced industries from countries as the United States and Czechoslovakia.

Keywords: industrialization; rationalization; management.

\footnotetext{
* Universidade Federal do Recôncavo da Bahia (UFRB).vdrezende@yahoo.com.br
} 


\section{O LOCAL E O GLOBAL NA INDUSTRIALIZAÇÃO DA “CAPital do CALÇADO”}

Os primeiros registros da fabricação artesanal de calçados e selas de couro na cidade de Franca, localizada na região norte do estado de São Paulo, datam de meados do século XIX, quando a atividade estava relacionada à pecuária $\mathrm{e}$ à consequente oferta de matéria-prima. A inserção do município no complexo cafeeiro dinamizou sua atividade manufatureira - em especial aquela relacionada ao fabrico do couro e de seus artefatos -, a partir da acumulação de capitais e das transformações econômicas, sociais e culturais resultantes da integração de mercados promovida pela cafeicultura e pela ferrovia. ${ }^{2}$

Durante as quatro primeiras décadas do século XX, a produção de couros foi a principal atividade industrial da economia local. Não obstante, com exceção do Curtume Progresso, que empregava cerca de noventa operários e chegou a ser o maior do interior paulista - mantendo-se entre os cinco maiores do estado, entre 1927 e 1938 -, os demais eram bastante incipientes. Do mesmo modo, a principal característica das manufaturas de calçados era o pequeno capital empregado, o predomínio do trabalho manual e a contratação raramente superior a vinte trabalhadores por unidade produtiva. Cumpre destacar que a produtividade dessas manufaturas estava condicionada à destreza dos oficiais sapateiros, os quais detinham o controle sobre os processos de trabalho e o ritmo da produção.

Os efeitos da Grande Depressão da década de 1930 contribuíram decisivamente para que a posição de Franca no cenário nacional fosse pouco a pouco se alterando. Frente à necessidade de reduzir custos de produção para conquistar um mercado consumidor mais amplo, as indústrias calçadistas dos grandes centros produtores, as cidades de São Paulo e Rio de Janeiro, foram se enfraquecendo. Ao mesmo tempo, Franca se beneficiou dos custos com mão de obra inferiores aos da capital do estado e especializou-se na produção de calçados rústicos destinados majoritariamente ao trabalho rural. Nesse mesmo período, a região do Vale do Rio dos Sinos (RS) especializou-se na produção de calçados femininos. ${ }^{3}$

Em meio à depressão econômica e às transformações dos processos de produção, ocorreu uma experiência de mecanização das fábricas de calçados de Franca que se revelou fundamental. Em meados da década de 1930, o industrial Antônio Lopes de Melo importou máquinas da Alemanha e pouco tempo depois a empresa norte-americana United Shoes Machinery Company (USMC) substituiu o maquinário alemão por equipamentos mais modernos mediante o sistema 
de leasing. ${ }^{4}$ Além de possibilitar o incremento da produção local de calçados, o sistema de arrendamento liberou os industriais de grandes dispêndios de dinheiro para a aquisição de máquinas, fator importante num cenário em que predominavam fábricas de pequeno porte e escassez de crédito oficial.

O crescimento das fábricas de calçados fez que, a partir de 1945, esse segmento superasse os investimentos na fabricação de couros e se constituísse na principal atividade econômica do município. Na década de 1950, a expansão da produção calçadista em Franca intensificou-se ainda mais, com a consolidação das indústrias antigas e a abertura de novas fábricas, o mesmo ocorrendo com os curtumes. Tal situação proporcionou a verticalização das atividades e foram montadas fábricas de formas de madeira para modelagem de calçados, de artefatos de borracha, de adesivos, de embalagens e de outros insumos utilizados no fabrico de calçados. Desde então, Franca passou a ser conhecida como a "capital do calçado", por causa da condição de principal produtora nacional de calçados masculinos de couro.

Como destaca Agnaldo Barbosa (2006, p.118-124), a USMC teve grande importância para o desenvolvimento e consolidação do setor no interior paulista, visto que foi credora de várias indústrias que tinham dificuldades de financiamento, mesmo com o incremento dos mecanismos creditícios no segundo governo Vargas (1951-1954), que contemplou principalmente as indústrias metalúrgicas, automobilísticas, químicas, farmacêuticas e de bens de consumo duráveis. Além disso, o crédito informal, obtido junto a particulares, também foi importante fonte de financiamento para as indústrias locais.

O desenvolvimento industrial de Franca atingiu seu ápice nos anos subsequentes ao golpe civil-militar de 1964, quando o setor calçadista brasileiro como um todo se beneficiou dos incentivos fiscais advindos do governo militar, promotor de uma política de estímulo às exportações de manufaturados, e as fábricas francanas começaram a exportar calçados em 1971. Portanto, a formação e consolidação do setor coureiro-calçadista de Franca fez parte das transformações mais amplas do capitalismo industrial numa perspectiva global. Nacionalmente, inseriu-se numa conjuntura de industrialização, crescimento urbano e concentração populacional nas cidades. Internacionalmente, respondeu à busca por produtores de bens de consumo não duráveis fabricados a preços mais baixos e competitivos, graças aos salários reduzidos de sua força de trabalho. Como ressaltou Achyles da Costa,

o ingresso do Brasil no mercado internacional de calçados ocorre a partir de um movimento em que se desloca a produção desse bem de consumo - e de outros 
produtos intensivos em mão de obra - dos países desenvolvidos em direção a regiões com oferta abundante de força de trabalho. Adicione-se, ainda, que o final da década de 1960 constitui-se na fase derradeira dos chamados "anos dourados", período de acelerado crescimento econômico que se iniciou ao término da Segunda Guerra Mundial. Nessa fase de prosperidade, a taxa de salários se elevou nos países desenvolvidos, encarecendo a fabricação de produtos que requeriam elevado conteúdo de trabalho direto. (Costa, 2004, p.15)

Desse modo, os salários mais baixos dos operários de Franca e do Vale do Rio dos Sinos, que haviam possibilitado a essas regiões se destacarem na produção nacional de calçados na conjuntura pós-crise de 1929, continuaram a ser cruciais, nos anos 1960, para a expansão do setor e para sua inserção no mercado internacional. $\mathrm{O}$ relato de um dos maiores exportadores brasileiros de calçados no começo dos anos 1970 sintetiza a questão:

A Espanha, a Itália, a Inglaterra podem fazer sapatos mais baratos do que nós? Efetivamente, não ...

Motivo para a certeza de conquistar os mercados norte-americanos: as fábricas de calçados dos Estados Unidos não têm condições de competir com nenhuma outra, de qualquer outro país, por causa da mão de obra ...

Por isso, enfrentando uma concorrência assim fraca, a obrigação do empresário brasileiro é ocupar o mercado ... Já recebemos do governo excelentes incentivos. Só falta que todos se decidam a aproveitar esses incentivos. Em que país existem condições como as nossas, sem problemas trabalhistas, sem greves, com mão de obra barata? É o nosso grande argumento para ter certeza do sucesso. ${ }^{5}$

Como indica esse excerto, a competitividade da indústria brasileira estava diretamente relacionada ao menor custo da força de trabalho, o que foi determinante para sua inserção internacional na produção e circulação de mercadorias, já que esse tipo de produto havia encarecido nos países tecnologicamente mais avançados por conta do fortalecimento do poder de negociação de seus trabalhadores. Assim, o arrocho salarial e a repressão ao movimento operário organizado, por parte do governo militar, mostraram-se decisivos para a exportação de calçados brasileiros para países como os Estados Unidos, maiores compradores desse produto, podendo ser interpretada como uma das estratégias dos empresários internacionais para aumentar suas margens de rentabilidade e enfraquecer o poder de negociação dos trabalhadores estadunidenses desse setor. Nos anos 1980 ocorreu a abertura mais significativa do 
mercado internacional, e as maiores empresas exportaram para países de diferentes continentes: Alemanha, Bélgica, Dinamarca, França, Holanda, Inglaterra, Itália, Polônia, China, Japão, Argentina, Chile e Venezuela.

\section{A IMPORTAÇÃO DE MÁQUINAS E AS VIAGENS DOS INDUSTRIAIS AO EXTERIOR}

Para além dos baixos salários do operariado brasileiro, em especial dos sapateiros de Franca, as maiores indústrias da cidade foram capazes de exportar seus produtos a partir dos anos 1970 por conta da modernização e racionalização dos processos produtivos, em especial, no transcurso da segunda metade do século XX. Para tanto, os industriais locais realizaram diversas viagens ao exterior, importaram máquinas e contaram com a atuação crucial, no interior de suas unidades produtivas, de profissionais especialistas em gestão de processos produtivos e em relações de trabalho. Dessa maneira, para se compreender a inserção do complexo coureiro-calçadista brasileiro nos processos globais de produção e circulação de mercadorias, analisarei como se deu a importação de técnicas e de tecnologias.

Uma das principais características do parque fabril de Franca foi sua heterogeneidade. O primeiro Censo Empresarial realizado pelo Sindicato das Indústrias de Calçados de Franca (STIC), nos anos 1980, recenseou quatrocentas unidades produtivas, que em conjunto empregavam 28.508 funcionários e tinham uma capacidade de produção anual de mais de 36 milhões de pares de calçados. Do total de indústrias recenseadas, 218 empregavam até 20 pessoas, 81 empregavam de 21 a 50 pessoas, 69 empregavam de 51 a 200 pessoas e 32 , acima de 200 pessoas. ${ }^{6}$ Um setor industrial caracterizado por tamanha diversidade possuía fábricas em estágios tecnológicos bastante distintos. Assim, a análise que segue centrar-se-á na racionalização do trabalho nas maiores empresas, por serem elas as que estabeleceram ligações regulares com o exterior.

Ao optar pelo termo "racionalização", ao invés de "taylorismo" e "fordismo", recorri a um conceito que não reduz as transformações dos processos de produção e das relações de trabalho às ideias e realizações de Frederick W. Taylor, seus discípulos e Henry Ford. Com isso, não pretendo sugerir que esses termos sejam descartados, pois são amplamente utilizados para se interpretar um modelo de dominação social que teve como fundamento retirar dos trabalhadores o controle sobre os processos produtivos e transferi-lo para o pessoal 
especializado em gerir a força de trabalho. Assim, considero que tais termos devem ser problematizados, visto que várias inovações organizacionais, relacionais e tecnológicas tiveram outras matrizes teóricas e alguns de seus formuladores eram antagonistas declarados dos princípios taylorianos. Por isso, entendo que racionalização faz referência ao processo mais amplo de elaboração e aplicação de métodos de controle da força de trabalho que tiveram como objetivo primordial intensificar a produtividade dos trabalhadores e, em alguns casos, minimizar os conflitos sociais no ambiente de trabalho.

Feita essa ressalva, cabe destacar que a fabricação exclusivamente manual de couros em Franca teve duração relativamente curta, pois no começo do século XX os curtumes mecanizaram diferentes etapas do curtimento. A primeira experiência de mecanização ocorreu no Curtume Cubatão, após a viagem de seu proprietário ao Rio Grande do Sul para conhecer o processo de curtimento ao cromo. Dessa viagem resultou a importação, em 1913, de maquinário alemão apto a executar quase todas as operações da fabricação de couros. No final da década de 1910, o Curtume Progresso também foi ampliado e dotado de "métodos mais racionais", realização diretamente relacionada à contratação de "experimentados" técnicos e à importação de vários tipos de máquinas, ambos de origem alemã (Rinaldi, 1987, p.16).

Desse modo, a mecanização da fabricação de couros ocorreu bem antes do período de maior desenvolvimento do setor e se baseou na importação de máquinas e de técnicos. Nas décadas seguintes, observou-se o aperfeiçoamento das máquinas existentes, o desenvolvimento de novas máquinas, de insumos produtivos - com destaque para os produtos químicos -, a incorporação de técnicas de curtimento modernas e a maior divisão dos processos de trabalho, com a especialização dos trabalhadores na execução de uma única tarefa. A combinação dos novos insumos com o maquinário resultou na enorme redução do tempo necessário para o curtimento das peles.

Durante a primeira metade do século XX, praticamente todo o maquinário dos curtumes foi importado e os principais fornecedores eram a Alemanha, a Tchecoslováquia e a Itália. Os altos custos dos equipamentos mais modernos acarretavam a defasagem dos curtumes nacionais em relação aos curtumes europeus e estadunidenses. Nos anos 1950 e 1960, foram instaladas indústrias de máquinas para curtumes no Brasil, na região do Vale do Rio dos Sinos, mas o maquinário importado tinha maior qualidade. Não por acaso, em 1973, Pratini de Morais - ministro da Indústria, Comércio e Turismo - apontou a necessidade de pesquisas e melhoramentos do calçado brasileiro e enfatizou a insatisfação governamental "com a qualidade dos equipamentos fabricados no 
Brasil para curtumes e indústrias de calçados. Devemos manter nível de qualidade e produtividade". Por isso, "é preciso que a indústria de máquinas melhore seus produtos, aproveite os incentivos do Governo e importe a tecnologia moderna para dar suporte adequado às indústrias". ${ }^{7}$ As fábricas nacionais de couro também sofriam com as dificuldades para a reposição de peças e muitas eram confeccionadas nas oficinas dos próprios curtumes, onde também se faziam aperfeiçoamentos, melhorias e desenvolvimento de máquinas.

No que se refere à mecanização da fabricação de calçados, o pioneirismo coube a Calçados Jaguar, que nos anos 1920 empregava máquinas europeias e algumas da USMC em seus processos produtivos. Conforme exposto anteriormente, a partir da segunda metade dos anos 1930, a utilização de máquinas arrendadas junto à USMC se intensificou. Além da mecanização da produção, para se compreender o crescimento daquela que veio a ser a maior fábrica de calçados de Franca, a Samello, é necessário apontar que a introdução do mocassim - modelo inspirado em calçados primitivos ${ }^{8}$ - foi fundamental não apenas para essa fábrica, mas para o desenvolvimento da indústria calçadista de Franca como um todo.

Em 1947, Miguel Sábio de Mello e seu filho primogênito, Wilson S. de Mello, viajaram aos Estados Unidos com o objetivo de conhecer as instalações da USMC. Em 1949, Miguel S. de Mello Filho seguido pelo irmão, Oswaldo S. de Mello, em 1951, foram enviados para estudar na Lynn Shoemaking School, em Boston, escola mantida pela USMC. A partir dessas viagens, o mocassim passou a ser fabricado na cidade de Franca. Esse modelo de sapato era mais confortável do que os predominantes até então. Além disso, representou uma grande inovação em termos de construção, pois, ao contrário dos outros sapatos, era montado de baixo para cima. ${ }^{9}$ Dessa maneira, a partir da recriação de um calçado primitivo e das campanhas de publicidade da Samello, que enfatizaram a flexibilidade, maciez, praticidade, leveza, conforto e o desenho moderno e inovador do mocassim, tornou-se possível a obtenção de enormes ganhos financeiros por essa empresa.

Após outras viagens feitas à Europa e aos Estados Unidos com o objetivo de conhecer novas técnicas de fabricação de mocassim, a Samello adquiriu um pantógrafo, transferidor que amplia e diminui o desenho copiado e permite fazer projetos em diferentes escalas com exatidão. Na produção de calçados, essa máquina possibilitava desenvolver toda a grade de produção e escalonar a numeração do sapato com precisão, resultando num produto de maior qualidade. Conforme afirmou Oswaldo S. de Mello, “com o pantógrafo nós conseguimos fazer o mocassim e ficou 15/20 anos sem que ninguém fizesse; então 
essa foi a nossa dianteira de [19]53 para $1970 . . . ”{ }^{10}$ Como se observa, a aquisição dessa máquina e o desenvolvimento de um novo modelo de sapato proporcionaram amplo domínio de mercado à empresa.

Além das transformações nos processos produtivos decorrentes da mecanização da produção e das novas concepções de construção do calçado, as maiores indústrias do setor transformaram significativamente seus espaços de produção. O pioneirismo também coube à Samello, que construiu um prédio amplo, funcional e moderno. Em 1954, Wilson S. de Mello realizou mais uma viagem aos Estados Unidos e assinou um contrato de consórcio com a organização General Shoes Corporation para a construção de um prédio segundo os planos elaborados por departamentos técnicos daquela empresa.

O novo prédio, inaugurado em 1956, tinha área construída de $6.470 \mathrm{~m}^{2} \mathrm{e}$ capacidade projetada para produzir 3.600 pares diários. $\mathrm{O}$ amplo salão principal, construído em concreto armado, era arejado, bem iluminado e comportava o maquinário instalado e disposto segundo o layout das firmas norte-americanas. Possuía ainda áreas para depósitos, estufa, cartonagem e oficina mecânica, e estavam em fase de acabamento as dependências conexas. ${ }^{11}$ A construção dessa unidade fabril atesta a incorporação de tecnologia estrangeira e a importância da ligação entre a Samello e empresas dos Estados Unidos. Ao analisar as transformações na arquitetura e na construção das fábricas estadunidenses, Daniel Nelson (1975, p.15-16) destacou que a USMC foi a primeira grande fábrica norte-americana a adotar a construção com concreto armado, em 19031904. A iniciativa atraiu grande atenção e iniciou a tendência de construção com essa técnica, que se espalhou por outras fábricas nos anos seguintes.

Contudo, a simples transposição de um projeto desenvolvido em outro país trazia inconvenientes se não fossem levadas em conta as peculiaridades do local a ser executado. Conforme relatou um dos proprietários da Samello, o projeto do prédio "tem um problema que nós, infelizmente, só fomos notar na prática. O pé direito da nossa fábrica é baixo, porque seguiu a planta americana, feita para um ambiente de calefação etc.". ${ }^{12}$ Isso fez que as cópias das plantas cedidas a outros industriais fossem acompanhadas da recomendação de se elevar o pé direito de 6 para 10 ou 12 metros, altura mais adequada às condições locais.

Esse caso evidencia que a relação entre as indústrias nacionais e as estrangeiras implicava um processo de absorção e, ao mesmo tempo, de recriação da tecnologia importada, que tinha de ser adaptada e transformada. A adaptação e a modificação da tecnologia importada de acordo com a realidade e as necessidades locais foi prática recorrente no processo de introdução do 
maquinário, conforme ilustra o caso de Fausto José Pimenta, mecânico da Samello eleito Operário Padrão de Franca em 1978:

Seu trabalho no aperfeiçoamento e construção de máquinas é uma constante, sempre visando Segurança e Aumento de Produção. - Construiu máquina de ensacar mocassim, baseando-se em máquina vinda da Espanha. - Adaptou máquina de calçar mocassim e bota, também baseada em uma vinda da Espanha. - Um de seus grandes trabalhos foi a adaptação das esteiras ... - Criou a máquina de moldar Gáspea, através de outra máquina vinda dos Estados Unidos ... - A confecção do ferramental das máquinas de montar bico é de sua responsabilidade. A máquina é proveniente da USM da Alemanha e todo o tipo de ferramental é construído aqui na empresa ... $90 \%$ das peças usadas na fábrica passam por suas mãos. ${ }^{13}$

Portanto, o papel dos mecânicos locais nesse processo de adaptação, aperfeiçoamento e desenvolvimento tecnológico foi central para o desenvolvimento do setor como um todo.

Nos anos 1950, as maiores fábricas de calçados de Franca estavam amplamente mecanizadas, possuíam prédios projetados especificamente para a produção industrial, os processos de trabalho eram cada vez mais fragmentados e, consequentemente, os trabalhadores parcelares tendiam a substituir os antigos sapateiros virtuosos. ${ }^{14}$ Restava então modificar o transporte interno do produto entre os diferentes postos de trabalho durante sua fabricação, pois a divisão do trabalho e o ordenamento sequencial das tarefas demandavam racionalizar o deslocamento do objeto em fabricação de um trabalhador a outro.

Uma primeira forma de organizar o transporte interno dos sapatos em fabricação foi por meio de carretas transportadoras empurradas pelos próprios trabalhadores à medida que realizavam suas tarefas, o que condicionava o ritmo de trabalho à velocidade dos operários. O controle externo da velocidade do trabalho por meio de um artefato metal-mecânico fora executado décadas antes na indústria automobilística e nas maiores empresas calçadistas de outros países, como a Bata - grupo industrial de origem tcheca -, pioneira na instalação das linhas de montagem na fabricação de calçados.

Tomas Bata, fundador da empresa, realizou diferentes viagens aos Estados Unidos e, em 1919, visitou a fábrica de Henry Ford instalada em Detroit, onde teve a oportunidade de ver em funcionamento a linha de montagem. Em 1927, foram instaladas linhas de montagem nas seções de pesponto (costura), montagem e acabamento da Bata em Zlin, Tchecoslováquia, como parte de um processo mais amplo de reorganização do trabalho que englobou a planificação 
da produção, um sistema de autonomia das oficinas e a instalação de cadeias de fabricação. A partir dessas inovações, a produção diária de calçados da fábrica passou de 8 mil pares em 1923 para 75 mil pares em 1928 e atingiu 168 mil pares em $1935 .{ }^{15}$

De acordo com o tecnólogo do calçado Zdenek Pracuch, a primeira linha de montagem de calçados da indústria brasileira foi instalada numa fábrica de propriedade de imigrantes tchecos estabelecida em Salvador (BA), a Mirca S.A., ${ }^{16}$ sendo ele o gerente industrial responsável pela organização da produção. Em uma das viagens de Wilson S. de Mello ao exterior, este teria conhecido a antiga Bata na Tchecoslováquia e se impressionado com seu sistema de organização do trabalho. Na ocasião, soube da existência da fábrica instalada em Salvador que funcionava segundo o sistema Bata. No início dos anos 1960, Pracuch saiu da Mirca e foi trabalhar em São Paulo. Wilson S. de Mello o procurou e o convidou a conhecer a Samello, onde o tecnólogo tcheco deparou com esta realidade:

Então, tinha um mar de carretas. Tinha um mezanino e paredes de vidro. O pessoal até chamava... dizia que era televisão [escritórios envidraçados de frente para a produção]. Tava sentado assim, virei a cadeira e olhei aquilo, meu Deus do céu! Nem Cristo acerta! ... Porque isso não é só botar a esteira, tem uma infraestrutura organizacional que tem que ser preparada pra esteira funcionar. Tudo vai depender de falhas no suprimento, falhas mecânicas, mau planejamento. Senão os operários ficam lá de braços cruzados, olhando um para o outro e a esteira vai andando vazia. ${ }^{17}$

Portanto, a introdução da linha de montagem demandava a prévia reorganização de toda a infraestrutura produtiva. A esteira, como ficou conhecida no setor calçadista, possibilitou o aumento da produtividade por retirar o controle do tempo de trabalho dos operários, mas sua introdução foi um entre outros componentes da racionalização do trabalho, que englobou aspectos técnicos e disciplinares, o desenvolvimento do setor de planejamento e a profissionalização da gestão. "Uma economia fundada em uma tecnologia muito sofisticada deve caracterizar-se por uma detalhada divisão do trabalho e por diretores formados profissionalmente que monopolizem suas funções de planificação, de gestão e de supervisão" (Montgomery, 1985, p.11, tradução minha). Como um dos elementos da racionalização, a linha de montagem tornouse símbolo do reordenamento da sociedade sob os princípios da fragmentação, especialização e disciplinarização dos trabalhadores. 
No caso da Samello, que produzia quatro modelos de sapatos, cada um com características distintas de fabricação, foi necessário cronometrar cada tarefa, levar em consideração tempos de secagem de colas e elaborar um complexo planejamento de suprimentos para se montar um layout funcional. A partir desses estudos prévios, em 1965 foi introduzida a primeira esteira na fabricação de calçados em Franca, construída por uma empresa paulistana de transportadores mecânicos para indústria automobilística, pois não houve autorização do governo federal para a importação por existir similar nacional. Esse equipamento possibilitou reduzir custos com insumos como formas de modelagem, ganhos de produtividade e o maior controle da força de trabalho pela gerência. Conforme afirmou Idacir Ferreira, gerente da Calçados Agabê ao longo de quase 30 anos,

a esteira nada mais é do que um chefe de produção, um gerente de produção. Porque quando você tem a esteira numa empresa, você não precisa de gerente de produção ... você vai dirigir qualidade. Você vai trabalhar em cima da qualidade, porque a produção ela puxa, ela se encarrega da produção ... Então a esteira foi uma revolução ... Eu jamais deixo de trabalhar com esteira. ${ }^{18}$

A revolução organizacional possibilitada por esse mecanismo levou as esteiras a se generalizarem entre as maiores fábricas de Franca e a produção em linha de montagem a se constituir no principal sistema produtivo da segunda metade do século XX.

RaCiOnAlizaÇÃO E "RELAÇÕES humanas":

A IMPLANTAÇÃO DO TWI EM FranCA

Em meio à racionalização do trabalho, destacou-se a necessidade de qualificar o pessoal dedicado à gestão dos processos produtivos no chão de fábrica: chefes de seção e gerentes. O predomínio dos supervisores advindos do meio operário e que exerciam os cargos de comando sem receber qualquer treinamento prévio ou instruções formais a respeito de como liderar e dirigir uma seção de trabalho foi uma prática recorrente no processo de industrialização. Justamente por isso, diferentes métodos e sistemas de qualificação da chefia foram formulados internacionalmente, entre os quais o método de treinamento de supervisores Training Within Industry (TWI), difundido entre diferentes países ao longo dos anos. 
A formulação do TWI ocorreu nos Estados Unidos, numa conjuntura marcada pela aproximação mais efetiva entre as ciências sociais emergentes e o Estado. O método foi um dos desdobramentos da escola de "relações humanas" no trabalho. Por meio de experimentos realizados em Hawthorne, iniciados em 1927 na Western Eletric Company, Elton Mayo e Fritz Roethlisberger demonstraram a importância de se ouvir os trabalhadores e de se preocupar com a satisfação deles no trabalho, fazendo que algumas empresas começassem a incentivar seus supervisores a serem mais sensíveis às necessidades dos trabalhadores e mais justos no tratamento. Mayo e Roethlisberger divergiram tanto do sistema tradicional de direção, centrado no autoritarismo do capataz, quanto da gerência científica de Taylor, que possuía uma visão mecanicista do trabalhador. ${ }^{19}$

Criado durante a Segunda Guerra Mundial, o TWI refletiu a necessidade crescente de desenvolvimento de programas de qualificação apropriada de mão de obra e teve como objetivo imediato contribuir para o treinamento do amplo contingente de trabalhadores que se dirigiram para as indústrias durante o esforço de guerra. Para tanto, o governo de Franklin D. Roosevelt implantou um escritório em Washington, ligado ao Conselho de Defesa Nacional, responsável pela elaboração do programa, que funcionou entre 1940 e meados de 1945, sob a coordenação de quatro engenheiros especialistas na gerência de pessoal (personnel manager).

O TWI foi composto por três cursos de treinamento intensivo, cada um com 10 horas de duração (cinco sessões de 2 horas). O primeiro curso, job instruction training (JIT), foi implantado nos Estados Unidos, em 1941, com o objetivo de preparar os supervisores para treinar e instruir os trabalhadores. O segundo curso, job methods training (JMT), foi incorporado ao programa nacional em meados de 1942 e visava decompor um trabalho específico em suas várias fases, rearranjá-lo e simplificá-lo. Era uma espécie de "curso reduzido em gestão científica humanizada" e visava capacitar os supervisores a conseguirem a maior produtividade possível sem abdicar da qualidade. O terceiro curso, job relations training (JRT), refletia mais diretamente o desenvolvimento da psicologia industrial durante o entreguerras e dava maior atenção ao "lado humano" do problema da gerência, passando a ser aplicado no começo de 1943. Em 1946, Channing R. Dooley - um dos engenheiros responsáveis pela elaboração do método - fundou a Training Within Industry Foundation para disponibilizar, adaptar, melhorar e ampliar os programas de treinamento e atender às necessidades imediatas da indústria e do comércio. ${ }^{20}$ 
No Brasil, o TWI foi introduzido no início dos anos 1950 e esteve ligado às atividades da Comissão Brasileira-Americana de Ensino Industrial (CBAI). Em São Paulo, ficou sob a responsabilidade da Secretaria do Trabalho, Indústria e Comércio. Segundo Flávio Sampaio, ${ }^{21}$ a introdução do método resultou da intensificação do crescimento industrial e da preocupação decorrente de os chefes (também chamados de mestres, supervisores, encarregados etc.) serem ex-operários sem conhecimentos prévios a respeito das técnicas de liderança, treinamento e relações de trabalho. O TWI foi considerado o método mais adequado para solucionar os problemas de falta de qualificação dos chefes em razão de suas características: comunicação rápida, ação intensiva, baixo custo, forma agradável e convincente de tratamento e conteúdo que abordava a instrução, as relações e a racionalização do trabalho. Em 1952, a CBAI o introduziu em caráter experimental nas cidades do Rio de Janeiro e de São Paulo, e, um ano depois, em função da imediata aceitação que teve, recomendou-se a sua implantação efetiva.

Em 1956, o TWI foi introduzido em Franca por intermédio e financiamento da Associação Comercial e Industrial de Franca (ACIF) e do Serviço Nacional de Aprendizagem Industrial (Senai). A realização do primeiro curso, Ensino Correto de um Trabalho, foi descrita como "uma grande oportunidade para ministrar conhecimentos técnicos aos chefes de seção das fábricas, do modo de lidar com os operários, e, principalmente, como 'comandar' o elemento humano dentro da fábrica”. Antes da realização do curso, Roberto de Aguiar Corrêa (chefe do setor de Organização do Treinamento e do escritório conjunto da Secretaria do Trabalho, Indústria e Comércio de São Paulo e CABI) visitou Franca e proferiu uma palestra para os industriais locais a respeito do TWI, definindo-o como "um método destinado a completar a formação dos supervisores, preparando-os a possuírem a capacidade de instruir o pessoal no trabalho, de liderar e de simplificar o trabalho". ${ }^{22}$

O curso foi realizado nas principais fábricas de calçados do município e na ACIF. Ao todo, foram treinadas cinquenta pessoas: chefes, gerentes e alguns industriais, como Wilson Sábio de Mello. As notícias jornalísticas indicaram a intenção de se retirar dos trabalhadores o controle sobre os processos de trabalho, pois um dos objetivos era habilitar os chefes a darem orientações claras e a instruir os trabalhadores sobre o que, como e quando fazer. Os chefes não deveriam deixar os trabalhadores decidirem como trabalhar, e para tanto, era preciso eliminar a empiria predominante na gestão do trabalho. "O problema de treinar mestres e supervisores consiste em conseguir substituir neles tradições errôneas de trabalho por atitudes mais metódicas e em seguir planos 
mais racionais." Destaca-se ainda a preocupação crescente com as relações entre chefes e trabalhadores: "segundo a moderna concepção de organização industrial, o elemento humano é que deve merecer, sobre os demais, a primeira atenção dos dirigentes de empresa". ${ }^{23}$

A experiência de capacitação de supervisores por meio do TWI não se restringiu ao ano de 1956. Nos anos 1970, o Serviço Social da Indústria (Sesi) ofereceu o curso de "Relações Humanas para o Trabalhador" e as empresas promoveram cursos em suas dependências e/ou patrocinaram a participação de seus supervisores em cursos oferecidos por instituições patronais diversas. Além disso, após a instalação da unidade do Senai em Franca, em meados dos anos 1970, os cursos de TWI foram ministrados com regularidade dentro das indústrias até o final dos anos 1980. O JIT treinou cerca de setecentas pessoas, o JRT cerca de 420, e o JMT pouco mais de quatrocentas pessoas. ${ }^{24}$ Também foram oferecidos cursos de Relacionamento humano e supervisão no trabalho (15 horas) e Relações humanas na indústria - introdução (10 horas). As indústrias de artefatos de borracha Amazonas e MSM, bem como as fábricas de calçados Samello e Sândalo, destacaram-se nos registros analisados, o que indica a preocupação das maiores indústrias do setor com a formação da chefia.

Em conjunto com os cursos de controle de qualidade, produtividade e "relações humanas", o TWI compôs o amplo movimento de racionalização do trabalho. Seus três cursos visavam aprimorar o treinamento dos trabalhadores, promover relações harmoniosas entre trabalho e capital, evitar conflitos no chão de fábrica, racionalizar os processos de trabalho e aumentar a produtividade ao diminuir as porosidades nos processos produtivos. Nesse sentido, o TWI indica a inadequação de se classificar toda e qualquer ação de racionalização do trabalho como fruto do taylorismo. Tais cursos faziam parte de um processo mais amplo de gestão de pessoal, composto por experimentos, formulações e realizações de diferentes teóricos e especialistas em gestão de processos de trabalho, e alguns desses métodos eram significativamente distintos daqueles defendidos por Frederick W. Taylor.

\section{“COMO ABElHAS POLINIZANDO FLORES"}

Conforme demonstrei até aqui, a difusão de tecnologias de produção e de técnicas gerenciais no setor coureiro calçadista de Franca se relacionou diretamente às iniciativas dos maiores industriais de visitarem países industrialmente mais desenvolvidos, importar maquinário, enviar alguns funcionários para conhecer ou estagiar em empresas estrangeiras e contratar técnicos 
formados em algumas das maiores indústrias mundiais de calçados. Por conseguinte, o pessoal dedicado à gerência industrial se constituiu no principal elo da síntese entre o local e o global, pois eram os principais responsáveis por difundir e reelaborar os sistemas disciplinares nas indústrias brasileiras, tendo como principal função fiscalizar a força de trabalho e controlar os processos produtivos. Segundo Braverman, "o controle é, de fato, o conceito fundamental de todos os sistemas gerenciais, como foi reconhecido implícita ou explicitamente por todos os teóricos da gerência" (1968, p.68, grifo meu).

Com o objetivo de aperfeiçoar seus processos produtivos, as empresas francanas de maior porte contrataram diferentes técnicos e profissionais com curso superior, alguns estrangeiros, para administrar setores estratégicos da produção. O Curtume Progresso, por exemplo, contratou técnicos alemães no final dos anos 1910 e continuou a empregar químicos estrangeiros nas décadas seguintes. Nos curtumes do Rio Grande do Sul, a contratação de técnicos estrangeiros - a maioria de origem alemã - tornou-se quase uma regra no final dos anos 1940 (Carneiro, 1986, p.103). ${ }^{25}$ Além dos químicos do Curtume Progresso, existem referências a respeito de profissionais estrangeiros contratados por outras indústrias do município: o grupo Samello contou com assessoria e assistência de modelistas, designers e técnicos de diferentes nacionalidades nos setores de produção e planejamento; a Amazonas - maior produtora de artefatos de borracha para calçados da América Latina - também contratou técnicos estrangeiros. Apesar de esses profissionais serem minoria nas indústrias de Franca, foram fundamentais para a introdução e difusão de sistemas gerenciais modernos.

Um dos personagens mais emblemáticos desse processo foi Zdenek Pracuch, contratado pelo grupo Samello nos anos 1960. Suas atividades e realizações estenderam-se por diversas empresas nacionais e internacionais, e ele pode ser considerado um dos principais expoentes da interação entre o local e o global no setor calçadista. Nascido na Tchecoslováquia, no ano de 1927, Pracuch entrou na Bata School of Labor, instalada em Zlín, aos 14 anos de idade, e formou-se em 1945. Seus anos de aprendizado ocorreram no período de ocupação alemã do território tcheco, e sua trajetória dentro da empresa foi abortada pelos desdobramentos da Segunda Guerra Mundial. Jan Bata assumira a administração da organização depois da morte do irmão Tomas, mas exilou-se nos Estados Unidos após a ocupação nazista e posteriormente se fixou no Brasil. Pracuch trabalhou na organização até 1948, quando os comunistas tomaram o poder e ele fugiu para a Alemanha. Receoso de permanecer na Europa frente à expansão comunista, migrou para o Brasil em maio de $1949 .{ }^{26}$ 
A Bata School foi fundada por Tomas Bata, em 1924, com o objetivo de formar trabalhadores e dirigentes industriais por meio de um sistema educacional que combinava a educação teórica com assuntos técnicos e comerciais no local de trabalho. Para tanto, os jovens trabalhavam durante o dia e tinham aulas no período noturno. Após os 3 anos de internato, almejava-se que os formandos tivessem desenvolvido engenhosidade e iniciativa para trabalhar em qualquer empresa. Em pesquisa realizada no final dos anos 1920 pelo International Labour Office, esse sistema de trabalho e ensino foi definido como uma disciplina militar, caracterizado por normas de conduta rígidas. ${ }^{27}$

Thomas J. Bata se referiu ao sistema de ensino criado por seu pai como um dos fatores responsáveis pelo maior atributo da organização: o espírito dos empregados, o verdadeiro orgulho de fazer parte da fábrica. A escola oferecia cerca de mil vagas anuais e chegou a receber 20 mil candidatos, o que se explicava pela concepção de que ser um "Bataman" ("homem Bata”) era um símbolo de distinção, prova da capacidade do indivíduo de pertencer a uma das mais exigentes e dinâmicas empresas da Tchecoslováquia. Isso fez que muitos egressos da Bata School ocupassem posições de responsabilidade dentro da organização e fossem pioneiros na sua expansão para a Índia, a Indonésia e a América Latina (Bata; Sinclair, 1990, p.3).

Formado nesse sistema que aliava prática, teoria, código de conduta moral e uma rígida disciplina, Zdenek Pracuch, na condição de executivo do grupo Samello nos anos 1960, foi responsável por inúmeros melhoramentos e transformações nos cálculos de custos, planejamento de produção, racionalização dos processos de trabalho e implantação da linha de montagem. Suas atividades não se restringiam aos processos produtivos e envolveram o acompanhamento da instalação e ampliação da rede de lojas Samello. A constante pressão por resultados por parte de Wilson S. de Mello ocasionou-lhe um esgotamento mental e resultou numa crise nervosa. Foi colocado em repouso absoluto por ordens médicas e tomou a decisão de sair do grupo. Nesse meio tempo, recebeu nova oferta para ser o diretor industrial da Mirca, em Salvador. Por seu intermédio, o grupo Samello contou com mais dois tchecos formados pela Bata: Roberto Stavela, gerente de administração da fábrica de calçados, e Eugênio Pospisil, que gerenciou a MSM.

Após uma temporada na Bahia (1968-1972), Pracuch retornou a Franca para dirigir a Calçados Pestalozzi. De acordo com seu depoimento, o principal atrativo para voltar foi a proposta de ser professor num curso de técnico em calçados a ser instalado no município: "vi uma grande oportunidade de ensinar, de transferir aquilo que Bata me deu e criar uma geração daqueles 
realmente tecnólogos do calçado". Em 1972, foi fundada a Faculdade Pestalozzi de Ciências, Educação e Tecnologia, realização inserida no processo mais amplo de qualificação de mão de obra e de formação de técnicos para o setor. No mesmo ano, noticiou-se o projeto de criação de um curso em nível superior, a ser instalado na referida faculdade, para a formação de profissionais para o fabrico do calçado. ${ }^{28}$

O projeto foi efetivado nos anos seguintes e resultou na implantação do curso "Tecnologia em fabricação de couro e calçados”. Romeu Caetano Cintra, aluno da primeira turma, relatou que o curso tinha duração de 2 anos e meio e era voltado para a formação de diretores industriais: oferecia um conhecimento panorâmico de processos de produção e administração industrial e enfatizava o conhecimento prático a ser utilizado no dia a dia. A maior parte do corpo docente era composta por funcionários das maiores indústrias locais e o currículo englobava disciplinas como cálculo de custos, modelagem de calçados, planejamento, química, técnicas e processos de fabricação, além de noções de organização científica do trabalho. Entre os professores, figurava o alemão Fering Paulix, professor de química e um dos responsáveis pela fundação da fábrica de adesivos da Amazonas; o italiano Novello Capelli, professor de iniciação à modelagem e modelista bastante renomado que trabalhou na Samello e na Pestalozzi, onde também foi diretor industrial; e Zdenek Pracuch, professor de processos de fabricação de calçados. ${ }^{29}$

Concomitante à instalação desse curso, Pracuch comandou a montagem do Centro de Tecnologia de Couros e Calçados, criado em abril de 1974. O jornal Atualizado noticiou a importação, com recursos da Fundação Pestalozzi, de um moderno laboratório para a realização de testes químicos e físicos proveniente da Inglaterra. Entre outras atividades, o Centro desenvolveu pesquisas para definir padrões corretos para a utilização de colas: temperatura, umidade relativa, secagem, pressão e uso de aceleradores. A colagem fora apontada como o principal problema pelos industriais da época, pois a aplicação de colas se difundira sem o devido conhecimento científico sobre sua utilização. ${ }^{30}$

$\mathrm{Na}$ Pestalozzi, Pracuch foi ainda um dos principais responsáveis pelas negociações com importadores dos Estados Unidos, que resultaram no início das exportações da empresa. Posteriormente, foi diretor da fábrica de calçados Makerli e coordenou a transferência da unidade de São Paulo para Franca, com produção diária de 6 mil pares de calçados. Em 1976, assumiu a direção da fábrica Camilo Ferrari em Limeira (SP) e, no final dos anos 1970, aceitou o convite para gerenciar uma fábrica de calçado instalada em Itajubá (MG), de propriedade da família Bata. Foi também representante da Nike junto à empresa 
francana N. Martiniano, que fabricou cabedais (parte superior do calçado) para a multinacional, dentre outras assessorias prestadas a empresas multinacionais. O cargo de diretor industrial em Itajubá foi exercido até o começo dos anos 1980, quando se aposentou e se tornou consultor no setor calçadista. Além dessas atividades, desde meados dos anos 1970 prestou serviços à empresa sueca F. Hollander - holding do setor calçadista - e viajou para diversos países para realizar negócios, vínculo que se manteve até os anos $1990 .{ }^{31}$

Após se aposentar, a trajetória de Pracuch se cruzou novamente com a de Romeu Cintra - que entre outras atividades, havia realizado um curso de um ano de duração na Alemanha nas áreas de administração, desenvolvimento estratégico e marketing - e os dois fundaram a Editora do Calçadista, destinada a prestar consultoria em O \& M (Organização e Métodos), oferecer cursos (Cálculo de custos de calçados, Chefia e liderança, Colagem, Organização e métodos de trabalho e Planejamento), seminários, congressos, além de editar um periódico e livros técnicos. A editora publicou o jornal O calçadista, especializado em assuntos do setor coureiro-calçadista, com periodicidade mensal e circulação nacional, e dois livros técnicos de autoria de Pracuch (1980; 1981).

O jornal O Calçadista foi lançado em março de 1980 e publicado até 1985. No editorial inaugural foi apresentada sua plataforma: ser uma publicação técnica, educativa e polêmica, destinada a representar o setor, reivindicar seus direitos, divulgar lançamentos, promover empresas, alertar e esclarecer para uma condução segura dos negócios a respeito de medidas e decisões, leis e normas, processos e técnicas, fluxos e rotinas. Seria "um veículo de ORIENTAÇÃO mercadológica, administrativa e tecnológica”. ${ }^{32} \mathrm{O}$ periódico contou com colaboradores permanentes nas áreas de marketing e varejo e com colaboradores esporádicos, traduziu artigos sobre técnicas de produção, reeditou textos originalmente publicados em revistas especializadas do setor, publicou notícias sobre feiras nacionais, comércio exterior, economia e política, ampliações e históricos de empresas, entre outros temas.

Romeu Cintra e Zdenek Pracuch eram os principais autores do jornal e escreviam principalmente artigos na seção de “Tecnologia”, nos quais apontaram os principais entraves ao incremento da produtividade, os prejuízos decorrentes do desperdício de matéria-prima, da falta de planejamento e do mau aproveitamento da mão de obra. O principal objetivo dos dois era apresentar soluções para tais problemas, o que seria possível a partir da superação da empiria reinante nos processos produtivos. Os administradores "que realmente desejam trabalhar apoiados numa técnica de produção racional e objetiva", observavam, "devem se formar profissionalmente baseados em 
conhecimentos científicos reais, em vez de aplicarem métodos, além de arcaicos, empíricos". ${ }^{33}$

Os dois livros de autoria de Pracuch foram formulados, justamente, para difundir os processos de racionalização do trabalho e tornar as indústrias mais competitivas à medida que aumentassem a produtividade dos trabalhadores. Dentre os diferentes temas abordados destacam-se: divisão racional do trabalho em operações fragmentadas; layout de produção; métodos de seleção e treinamento adequado da força de trabalho para o exercício de tarefas específicas; planejamento de produção; cálculo e controle rigoroso de custos e de produtividade; redução de desperdícios de tempo e de matéria-prima; estudos de tempos e movimentos; a influência das condições de trabalho e dos sistemas de remuneração sobre a produtividade; superação do controle centrado na figura dos chefes de seção formados de maneira empírica e sem instrução formal. Além de disseminarem técnicas de controle elaboradas cientificamente - por meio da coleta preliminar de dados, análise e sistematização dos resultados - e aperfeiçoadas internacionalmente, os autores afirmavam a imprescindibilidade dos tecnólogos para o desenvolvimento industrial.

A trajetória e atuação de sujeitos sociais como Zdenek Pracuch, suas realizações e obras evidenciam a centralidade da gerência industrial para a inserção das indústrias brasileiras no mercado mundial de calçados. O tecnólogo tcheco radicado no Brasil tinha plena consciência de seu papel, como se verifica neste excerto:

Qualquer proprietário ou diretor de uma indústria está convencido que conhece a sua empresa como ninguém. Nada mais justo. Mas isso de conhecer bem a sua empresa não quer dizer muita coisa. A empresa não é uma ilha. No mínimo faz parte de um arquipélago. [A] avaliação de uma empresa só pode ser feita em função da comparação de empresas do mesmo ramo ...

Essa avaliação comparativa somente poderá ser feita por alguém de fora ...

Três anos de consultoria valem por 30 anos de vida em uma empresa. Por quê? Por exemplo: raramente um industrial constrói mais de uma fábrica em sua vida. Um consultor analisa um projeto ou faz um layout por mês, no mínimo. Quem tem mais probabilidade de acertar? ...

Como abelhas que voam de flor em flor polinizando todas, em benefício geral, assim também o consultor distribui os conhecimentos que acabam beneficiando todos. ${ }^{34}$ 
A primeira característica do texto de Pracuch é ser um artefato de publicidade com o fim de divulgar seus serviços de consultoria, buscando convencer os industriais da imprescindibilidade de contratar um consultor externo. Não obstante, os argumentos do autor possibilitam compreender o papel da gerência para integração entre o local e o global, pois os tecnólogos do calçado não se restringiam ao controle de uma única fábrica. Nesse sentido, eles podem ser definidos como organizadores coletivos dos processos de produção e trabalho, que exercem o controle por meio do domínio da técnica, empregada com o objetivo de racionalizar o trabalho e alcançar maior eficiência e produtividade.

Diretores industriais, gerentes e tecnólogos como Zdenek Pracuch não restringiram suas atividades a unidades particulares de produção e tampouco às fronteiras nacionais. Formular, aperfeiçoar e difundir técnicas de controle do trabalho e de administração industrial - por meio dos cursos, palestras, da publicação de periódicos e livros de cálculo de custos, de planejamento e de gerência científica etc. - foram ações que extrapolavam o âmbito local e que se destinavam à aplicação em quaisquer indústrias do setor. Desse modo, o papel exercido pela gerência industrial evidenciou que o capital é uma relação social global, destinado a intensificar o controle capitalista e, consequentemente, a exploração da força de trabalho, pois no sistema capitalista de produção, as unidades fabris não estão isoladas umas das outras, e sim integradas e articuladas entre si. Assim, a inserção de Franca no mercado internacional de calçados pode ser mais bem compreendida ao se considerar a importância das relações estabelecidas entre as indústrias nacionais e as estrangeiras, com atenção especial para a agência da gerência industrial.

\section{REFERÊNCIAS}

ARCHANJO, Francisco Miguel. “O mundo compreenderá". A história de Jan A. Bata - o rei do sapato. Rio de Janeiro: Aurora, 1952.

BARBOSA, Agnaldo de S. Empresariado fabril e desenvolvimento econômico: empreendedores, ideologia e capital na indústria do calçado (Franca, 1920-1990). São Paulo: Hucitec; Fapesp, 2006.

BATA, Thomas J.; SINCLAIR, Sonja. Bata: shoemaker to the world. Toronto, Canadá: Stoddart, 1990.

BRAVERMAN, Harry. Trabalho e capital monopolista: a degradação do trabalho no século XX. 3.ed. Rio de Janeiro: Zahar, 1981. 
BREEN, William J. Social science and state policy in World War II: human relations, pedagogy and industrial training, 1940-1945. The Business History Review, v.76, n.2, p.233-266, 2002.

CARNEIRO, Lígia G. Trabalhando o couro: do serigote ao calçado "made in Brazil". Porto Alegre: L\&PM; Ciergs, 1986.

CEKOTA, Anthony. Entrepreneur extraordinary. The biography of Tomas Bata. Rome, Italy: EIS; Ontario, Canada: T.H. Best, 1968.

COSTA, Achyles B. da; PASSOS, Maria C. (Org.) A indústria calçadista no Rio Grande do Sul. São Leopoldo, RS: Ed. Unisinos, 2004.

DIETZ, John Walter; BEVENS, Betty W. Learn by doing: the story of Training Within Industry, 1940-1970. Summit, NJ: Walter Dietz, 1970.

GABOR, Andrea. Filósofos do Capitalismo. Rio de Janeiro: Campus, 2001.

LE BOT, Florent. La 'famille' du cuir contre Batta: malthusianisme, corporatisme, xénophobie et antisémitisme dans le monde de la chaussure en France, 1930-1950. Revue d'Histoire Moderne et Contemporaine, Paris: Belin, v.52, n.4, p.131-151, 2005. MONTGOMERY, David. El Controle obrero en Estados Unidos. Estudios sobre la historia del trabajo, la tecnología y las luchas obreras. Madrid: Ministerio de Trabajo y Seguridad Social, 1985.

NAVARRO, Vera L. Trabalho e trabalhadores do calçado: a indústria calçadista de Franca (SP): das origens artesanais à reestruturação produtiva. São Paulo: Expressão Popular, 2006.

NELSON, Daniel. Managers and workers. Origins of the new factory system in the United States. 1820-1920. Madison: The University of Wisconsin Press, 1975.

PRACUCH, Zdenek. Cálculo de custo de calçados. Franca, SP: Ed. do Calçadista, 1980. . Organização e gerência do pesponto. Franca, SP: Ed. do Calçadista, 1981.

REZENDE, Vinícius de. Tempo, trabalho e conflito social no complexo coureiro-calçadista de Franca-SP (1950-1980). Tese (Doutorado em História) - IFCH, Unicamp. Campinas, 2012.

RINALDI, Dalva M. C. A indústria curtumeira em Franca. Relatório Trienal. Franca, 1987. (mimeo.)

ROE, Richard. The United Shoe Machinery Company. The Journal of Political Economy, v.21, n.10 (Dec. 1913), p.938-953 e v.22, n.1 (Jan. 1914), p.43-63.

SAMPAIO, Flávio Penteado. Experiência obtida no Brasil com a aplicação do método de supervisão TWI. Cadernos de economia Industrial. II série. n.14. São Paulo: DPI, 1953.

SCHACHTER, Ruth J. The art science \& of footwear manufacturing. Philadelphia: Footwear Industries of America, 1983.

SUZIGAN, Wilson. Indústria brasileira: origem e desenvolvimento. São Paulo: Hucitec; Ed. Unicamp, 2000.

TOSI, Pedro G. Capitais no interior: Franca e a história da indústria coureiro-calçadista (1860-1945). Franca: Unesp; FHDSS, 2002. 


\section{NOTAS}

${ }^{1}$ Este artigo resulta de pesquisa financiada pela Fapesp.

${ }^{2}$ Segundo Pedro Tosi, as influências das transformações da cafeicultura e seus efeitos sobre a indústria coureiro-calçadista foram significativos: proporcionou uma população operária urbana, uma fonte de renda agrícola que pôde servir de capital de empréstimo e "fez surgir um segmento médio junto a essa população urbana" que se envolveu na comercialização de couros e calçados (2002, p.119, 199).

${ }^{3}$ Sobre a relação entre a crise econômica e o desenvolvimento da indústria calçadista em Franca, cf. TOSI, 2002, p.165-168, 216. Para o desenvolvimento do setor no Vale do Rio dos Sino, cf. CARNEIRO, 1986, p.113.

${ }^{4}$ Fundada nos Estados Unidos, em 1899, a USMC ampliou o sistema de arrendamento de máquinas em tais proporções que, em 1911, respondeu na Suprema Corte pela acusação de monopólio. Cf. ROE, 1913/1914. Essa empresa instalou-se no Brasil na primeira década do século XX e foi determinante para a disseminação da maquinaria na fabricação de sapatos e para o barateamento do produto nacional. Cf. SUZIGAN, 2000, p.193-197.

${ }^{5}$ Jornal Comércio da Franca. "Industriais francanos precisam ser mais arrojados e agressivos”, 30 abr. 1971 (grifos meus). Entrevista com Vlastimir Arambasic, diretor da Arcoflex, instalada na cidade de São Paulo. A reportagem original foi publicada no Jornal da Tarde de São Paulo em 24 abr. 1971.

${ }^{6}$ SICF. Censo Empresarial de Franca (mimeo.), Franca, 1984, p.34, 36 e 61.

${ }^{7}$ Jornal Comércio da Franca. "Qualidade das máquinas para calçados preocupa o Governo", 12 jun. 1973.

8 "A construção do mocassim genuíno é uma simples peça de couro formando o fundo e a lateral do sapato e uma segunda peça, chamada 'plug' ['tampão'], formando o topo do sapato. Ficou claramente estabelecido que o calçado modelo-mocassim tem sido usado por milhares de anos", SCHACHTER, 1983, p.26 (tradução minha).

9 Sobre as viagens da família Sábio de Mello aos Estados Unidos, cf. BARBOSA, 2002, p.173. Para uma análise detalhada do processo de fabricação do mocassim, cf. REZENDE, 2012, p.44-45.

${ }^{10}$ Depoimento de Oswaldo Sábio de Mello a Agnaldo de S. Barbosa em julho de 2001.

${ }^{11}$ As informações a respeito da parceria industrial e da construção do novo prédio se baseiam nas seguintes reportagens do jornal Comércio da Franca: "Franca será industrialmente ligada aos Estados Unidos", 4 abr. 1954; "Bom dia Miguel Sábio de Mello e filhos", 20 jul. 1956; e "Samello - iniciativa arrojada e progressista", 12 out. 1956.

12 "Samello em sucessão: um legado", Lançamento, s.l., n.43, 1990, apud NAVARRO, 2006, p.96.

${ }^{13}$ Jornal Comércio da Franca. "É da Samello o 'Operário Padrão' de 78 de Franca", 1 set. 1978. 
${ }^{14}$ Em função da heterogeneidade do parque fabril francano e das características de fabricação dos calçados, a fragmentação do trabalho e a substituição dos trabalhadores virtuosos por trabalhadores parcelares não foi um processo retilíneo. Mesmo nas maiores indústrias, algumas tarefas continuaram a demandar trabalhadores com destrezas e conhecimento sobre a totalidade do processo produtivo. Cf. o capítulo 2 de REZENDE, 2012.

${ }^{15}$ Sobre as viagens de Tomas Bata aos Estados Unidos, cf. CEKOTA, 1968. Sobre o aumento da produção após a instalação da linha de montagem cf. LE BOT, 2005, p.134-135.

${ }^{16}$ O Decreto no 48.531, de 18 jul. 1960, assinado pelo presidente Juscelino Kubitschek declarava "prioritária ao desenvolvimento do Nordeste, para efeito de isenção de impostos e taxas federais, a importação dos equipamentos novos, ora descritos e a serem trazidos do exterior pela Mirca S/A. Indústria e Comércio, de Salvador (BA)”. Entre as mais de duzentas máquinas cuja importação fora autorizada pelo governo federal, constam quatro linhas de montagem da marca Svit, empresa do grupo Bata na Tchecoslováquia. Disponível em: http://legis.senado.gov.br/legislacao/ListaPublicacoes.action?id=179152; Acesso em: 18 jul. 2014.

${ }^{17}$ Depoimento de Zdenek Pracuch ao autor, 12 jan. 2009 (grifos meus).

${ }^{18}$ Depoimentos de Idacir Ferreira ao autor, 9 e 10 fev. 2009 (grifos meus).

${ }^{19}$ Cf. BREEN, 2002, p.235-237. Para uma análise sintética das realizações de Mayo e Roethlisberger, cf. GABOR, 2001, p.104-151.

${ }^{20}$ A síntese sobre o desenvolvimento do TWI baseia-se em BREEN, 2002, e DIETZ; BEVENS, 1970.

${ }^{21}$ Chefe do serviço técnico de produtividade da Secretaria do Trabalho, Indústria e Comércio, secretário geral da Comissão de Mão de Obra, diretor da Divisão de Ensino Industrial do Ministério do Trabalho, Indústria e Comércio. SAMPAIO, 1953.

${ }^{22}$ Excertos retirados do jornal Comércio da Franca. "Em Franca, o primeiro curso de aprendizagem industrial do Brasil”, 24 fev. 1956; “Aplicação do método TWI. Em março terá início o treinamento dentro da indústria em Franca”, 14 mar. 1956.

${ }^{23}$ Excertos e informações baseadas nas seguintes matérias do jornal Comércio da Franca: "Instalação do curso de 'Treinamento dentro da Indústria' em Franca”, 17 maio 1956; "Concluída a 1a fase do TWI em Franca", 26 maio 1956; "Curso de relações humanas para o trabalhador”, 29 dez. 1956.

${ }^{24}$ Sobre a oferta do curso pelo Sesi, cf. Comércio da Franca. "Sesi promove curso de Relações Humanas para o Trabalhador". 31 maio 1970. As demais informações baseiam-se na análise de documentos do Senai: Registro de Treinamento Industrial. 1976-1988.

${ }^{25}$ Pode-se relacionar o predomínio de técnicos alemães nos curtumes brasileiros ao desenvolvimento científico daquele país, pioneiro na incorporação da ciência à produção. Cf. BRAVERMAN, 1981, p.140-144.

${ }^{26}$ Jan Bata, com familiares e diretores da organização, exilou-se nos Estados Unidos em 1939, e em 1941 fixou residência no Brasil, onde fundou uma vila operária chamada Bata- 
tuba em Piracaia, distante 80 quilômetros da cidade de São Paulo, e instalou uma fábrica de sapatos, curtume, armazéns etc. Fundou ainda as cidades de Mariápolis (SP), Bataguassu (MS), Batayporã (MS) e Anaurilândia (MS). No Mato Grosso do Sul os negócios eram nos ramos de colonização, fazendas, olarias e serraria. Cf. ARCHANJO, 1952, e o depoimento de Zdenek Pracuch ao autor.

${ }^{27}$ Cf. INTERNATIONAL LABOUR OFFICE. Studies on industrial relations. Geneva, 1930, p.243. Além dessa obra, a análise sobre o sistema Bata de ensino baseia-se em CEKOTA, 1968, BATA; SINCLAIR, 1990, e no depoimento de Zdenek Pracuch ao autor, 12 jan. 2009.

${ }^{28}$ Depoimento de Zdenek Pracuch ao autor e jornal Comércio da Franca, "Calçados: curso de alto nível deve sair em julho", 16 abr. 1972.

${ }^{29}$ Depoimento de Romeu Caetano Cintra ao autor, 3 maio 2010.

${ }^{30}$ Atualizado: jornal do couro, do calçado e componentes. "Solução para os problemas da indústria francana: a tecnologia se encarregou disso”, Franca, ano 1, n.1, 8 a 16 jun. O jornal foi editado em Franca e lançado em 1974. Tinha periodicidade quinzenal e circulação nacional.

${ }^{31}$ A síntese biográfica de Zdenek Pracuch foi elaborada a partir de seu depoimento ao autor e de reportagem publicada em O Calçadista. "Zdenek Pracuch, de onde veio e quem é", Franca, ano 1, n.7, set. 1980, p.2.

32 O Calçadista. "Plataforma”, Franca, ano 1, n.1, mar. 1980, p.2 (caixa alta no original).

${ }^{33}$ Idem. "Curso 'Cálculo de Custo de Calçados’ vem cobrir carência do setor”, ano 2, n.15, jul. 81, p. 2 .

${ }^{34}$ Idem. Zdenek Pracuch. “O que faz um consultor?”, ano 3, n.41, dez. 1983, p.9 (grifos meus).

Artigo recebido em 7 de julho de 2014. Aprovado em 15 de outubro de 2014. 